\title{
Proposição de procedimento preventivo de riscos geológicos em Ouro Preto - BR com base em histórico de ocorrências e sua correlação com a pluviosidade
}

\author{
Jeanne Michelle Garcia Castro', Frederico Garcia Sobreira ${ }^{2}$, Romero César Gomes ${ }^{2}$ \& \\ Guilherme José Cunha Gomes ${ }^{3}$
}

\begin{abstract}
Resumo Devido ao grande número de movimentos de massa que ocorrem na área urbana de Ouro Preto (MG) foi desenvolvido um estudo para cadastrar os acidentes ocorridos entre 1988 a 2004, baseado nos registros dos Boletins de Ocorrência do Corpo de Bombeiro da cidade. Com esse cadastro foi possível elaborar um mapa com as áreas mais críticas da cidade, classificadas de acordo com o risco que apresentam em alto, médio ou baixo. Outra etapa do estudo foi a correlação dos escorregamentos com a pluviosidade. Para isto foi necessária a coleta de dados pluviométricos em uma indústria local. Deste estudo obteve-se uma equação correlacionando a chuva diária com a chuva acumulada em cinco dias anteriores ao acidente. Com a equação estabelecida podese estimar a quantidade de chuva diária necessária para provocar os escorregamentos. O trabalho finaliza com a proposição da implantação de um plano de defesa civil para Ouro Preto.
\end{abstract}

Palavras-chave: Movimentos de Massa, Pluviosidade, Ouro Preto, Plano Preventivo.

\begin{abstract}
Proposal of preventive procedure for geologic risks in Ouro Preto - BR based on the correlation between historical occurrences and rain. Due to the overwhelming number of mass movements which takes place in the urban area of Ouro Preto (MG), a study of accidents occurred between 1988 and 2004 has been developed, based on the city's Fire Brigade reports. It has then been possible to elaborate a map highlighting the most critical areas surrounding the city. Such areas were then tagged as low, medium and high risk. Another stage presented in the work was the correlation between landslides and rainfall. To obtain this, rain data had to be collected at a local plant. An equation has been obtained correlating the fallen rain on the landslide day and the accumulated rain from the five previous days which occurred before the accident. Once the equation was established, the amount of rain prompting landslides could be estimated. Based on this, a civil defense plan for the city is greatly recommended.
\end{abstract}

Keywords: Landslides, Rainfall, Ouro Preto, Preventive Plan.

INTRODUÇÃO Os altos índices de acidente relacionados a movimentos de massa em Ouro Preto promoveram o interesse de pesquisadores e resultaram em diversos trabalhos, abordando questões relacionadas com o uso e ocupação do solo e aos problemas geológicos/geotécnicos existentes na cidade.

Em 1975 a Fundação João Pinheiro realizou um estudo que abordou os aspectos físicos, socioeconômicos e administrativos para Ouro Preto e Mariana. Neste trabalho, apesar da preocupação com a ocupação da cidade, não foram desenvolvidos aspectos relacionados às características geológicas do local.

A Carta Geotécnica de Ouro Preto, desenvolvida por Carvalho em 1982 na escala de 1:2.000 foi uma tentativa de orientação da expansão da cidade. Foram realizadas as descrições das características físicas e geológicas locais e como produto final do trabalho foi elaborada uma Carta de Risco, baseada no cruzamento da Carta de Declividades com a Carta de Qualidade do Terreno, ambas também desenvolvidas neste trabalho. Apesar da Carta ser um bom indicador para a ocupação da cidade, ela não foi utilizada nem pelos moradores, nem pelo poder público, além da cidade atualmente ter crescido para além dos limites mapeados pela Carta Geotécnica de Ouro Preto.

Com a ocupação irregular, diversas situações de risco foram causadas. Sobreira (1989) apontou os pontos mais críticos da cidade em relação à instabilidade do terreno. Neste mesmo ano ocorreram fortes chuvas provocando vários danos materiais à população. Devido a essas chuvas foram elaborados dois relatórios, sendo um definindo as principais

1 - Núcleo de Geotecnia, Escola de Minas, Universidade Federal de Ouro Preto, Outro Preto (MG). Brasil. E-mail: jeanne.castro@pimentadeavila.com.br

2 - Núcleo de Geotecnia, Escola de Minas, Universidade Federal de Ouro Preto, Outro Preto (MG). Brasil. E-mail: sobreira@degeo.ufop.br, romero@em.ufop.br

3 - Departamento de Estradas de Rodagem do Estado do Espírito Santo, Vitória (ES), Brasil. E-mail: guilherme.gomes@der.es.gov.br 
áreas de risco e outro apontando algumas soluções estruturais.

Sobreira (1990) levantou as áreas de risco geológico e as áreas afetadas após as chuvas de 1989, apresentando novamente os locais mais problemáticos. Em outro relatório, Sobreira et al. (1990) apontaram algumas soluções para as áreas problemáticas de Ouro Preto, baseados em visitas de campo, lançamento das ocorrências em mapas e registro fotográfico. Já neste trabalho foram indicados como sugestão o cadastramento detalhado das áreas de risco e a criação de um sistema de defesa civil para a cidade.

Souza (1996) realizou novo mapeamento geotécnico da área urbana de Ouro Preto (escala 1:10.000) e avaliou os movimentos de massa e processos correlatos. Além do mapeamento geotécnico, foi proposta uma carta de zoneamento geotécnico voltada para a susceptibilidade à ocorrência de movimentos de massa.

Bonuccelli (1999) e Bonuccelli \& Zuquette (1999) elaboraram um estudo sobre os movimentos gravitacionais de massa e os processos erosivos em Ouro Preto, descrevendo os tipos de processos envolvidos, dimensões, materiais e estados de atividade. O levantamento dos movimentos foi realizado através de fotografias aéreas e trabalhos de campo, sendo também elaborado um cadastro dos movimentos de massa baseado nas ocorrências atendidas pelo Corpo de Bombeiros de Ouro Preto. Os autores apontam a urgência da criação de um plano de gerenciamento e minimização dos riscos associados aos movimentos de massa.

CARACTERIZAÇÃO DO MEIO FÍSICO A cidade Ouro Preto está situada na extremidade sudeste de região conhecida como Quadrilátero Ferrífero, na zona mínero-metalúrgica do Estado de Minas Gerais, a 90 km da capital, Belo Horizonte.

O clima é marcado pela elevada pluviosidade, com maior concentração entre os meses de outubro e março. Os verões são suaves, concentrando a maior parte da precipitação anual (entre dezembro e fevereiro) e os invernos chegam a registrar temperaturas negativas, com elevada umidade atmosférica. As características básicas são de um clima tropical de montanha, em que a baixa latitude é compensada pela altitude e conformação orográfica regional (Carvalho 1982).

A morfologia local caracteriza-se por altas montanhas de desenvolvimento linear, áreas aplainadas com altitudes diversas e vales alongados, muitas vezes bem encaixados. Cerca de $40 \%$ da área urbana exibe feições com declividades entre 20 a $45 \%$ e apenas 30\% com declividades entre 5 e $20 \%$. Zonas escarpadas são comuns em toda a área urbana (Gomes et al. 1998).
O relevo é acidentado com vertentes bem íngremes e vales profundos e encaixados. As altitudes estão em torno de $1.060 \mathrm{~m}$ nas partes mais baixas e $1.400 \mathrm{~m}$ no topo da Serra de Ouro Preto. A malha urbana estende-se ocupando tanto o vale principal, como as vertentes e contrafortes das serras que o delimitam.

O substrato é constituído por metassedimentos de idade paleoproterozoica - filitos, quartzitos, xistos e formações ferríferas - profundamente afetados por eventos tectônicos. É comum a ocorrência, nos topos e nas vertentes dos morros, de coberturas superficiais de crosta laterítica, localmente denominadas de "canga". Os solos, quando ocorrem, são muito pouco espessos, na ordem dos centímetros, exceto por algumas manchas maiores de material coluvial.

As litologias caracterizam-se por apresentar, além da foliação metamórfica marcante, descontinuidades planares (falhas e fraturas), que influenciam profundamente seu comportamento geotécnico. O estado de alteração e o intenso fraturamento das rochas contribuem ainda mais para o fraco comportamento geotécnico dos terrenos locais.

PLUVIOSIDADE Os dados pluviométricos utilizados no desenvolvimento do trabalho foram coletados na estação meteorológica de uma indústria local, localizada no bairro de Saramenha em Ouro Preto. A série estudada foi de 1988 a 2004. Para esta série a média pluviométrica anual encontrada foi de 1.610,1 mm, variando entre $1.005,1 \mathrm{a} 2.512,4 \mathrm{~mm}$.

A região de Ouro Preto possui alta pluviosidade, concentrada principalmente entre os meses de outubro e março, concentrando $87 \%$ da precipitação anual. Os meses mais chuvosos são dezembro e janeiro. A média diária de chuva encontrada foi de 4,4 mm, sendo que o máximo de precipitação diária, no decorrer do período analisado, foi de 115,2 mm em 18 de janeiro de 1991 .

Os dados horários das chuvas são mais apropriados para estudos de correlação entre escorregamentos e pluviosidade, analisando assim a intensidade no momento da deflagração dos escorregamentos. No entanto em Ouro Preto não existe nenhum posto de coleta deste tipo de dado. Mesmo assim foram realizados testes de consistência dos dados coletados na cidade com os de outras estações próximas para verificar a confiabilidade e representatividade destes. A figura 1 mostra as médias mensais históricas de precipitação em Ouro Preto.

\section{CADASTRO DOS MOVIMENTOS DE MASSA}

A coleta de dados foi dividida em duas etapas, sendo que a primeira consistiu na compilação dos dados de movimentos de massa e dos dados pluviométricos entre os anos de 1988 a 1998 do trabalho de Bonuccelli 


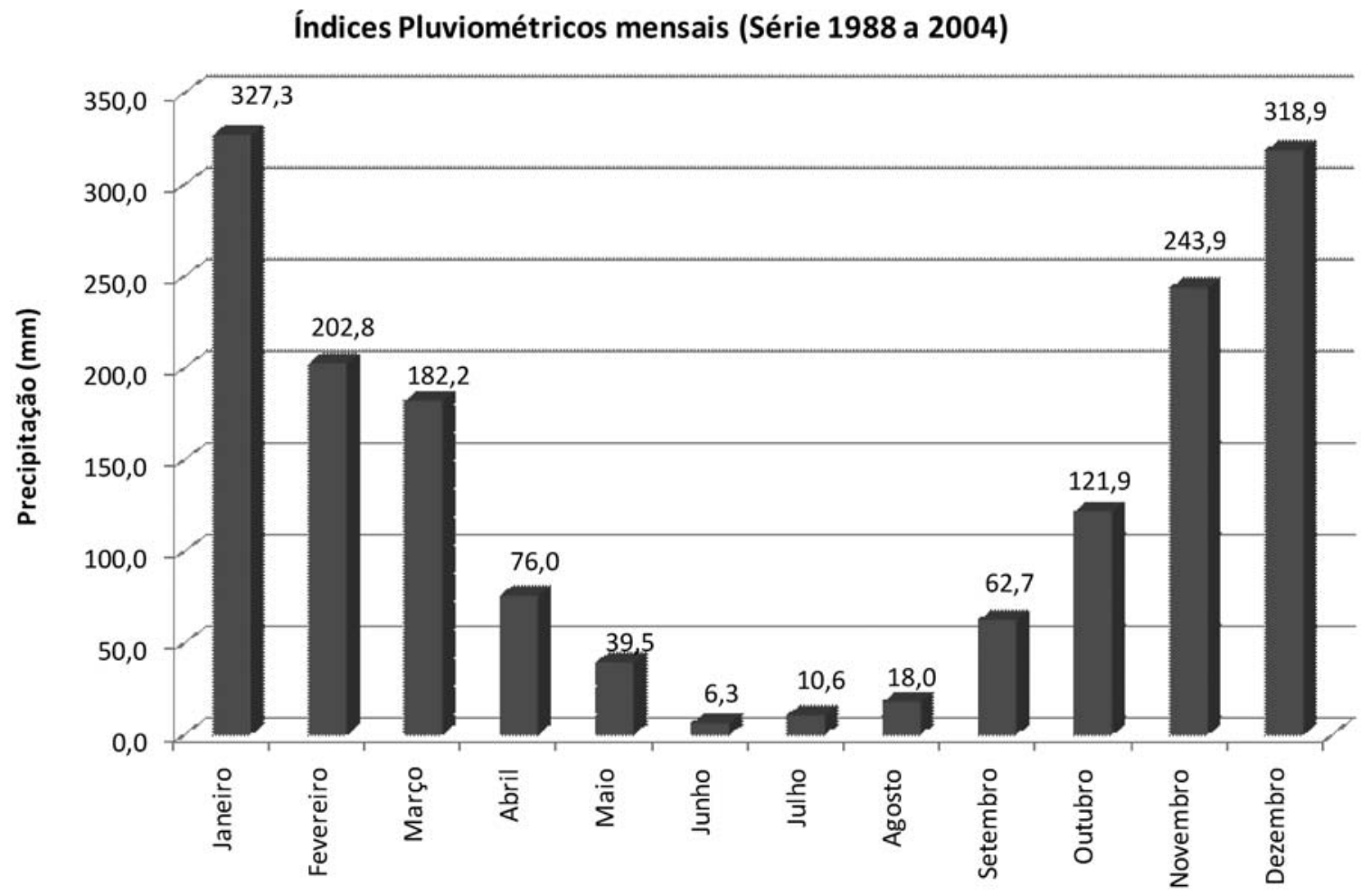

Figura 1 - Médias mensais históricas de precipitação em Ouro Preto.

(1999) e a segunda parte foi o complemento destes dados até o ano de 2004, utilizando as mesmas fontes de coleta.

O cadastro dos movimentos de massa foi retirado dos boletins de ocorrências do Corpo de Bombeiros da cidade, que é o responsável pelo atendimento a esse tipo de acidente. Através do registro dos Bombeiros foi possível obter as informações sobre a data, localidade e o tipo de acidente ocorrido. No entanto, a hora exata do acidente não foi registrada.

Foi realizada então uma triagem nestes dados, retirando-se as ocorrências não relacionadas com movimentos de massa, tais como inundações e possibilidades de ocorrência e registros não correlacionadas com chuvas (sem registro pluviométrico nos últimos 30 dias). Restaram 417 ocorrências para o cadastro final, sendo que $81,1 \%$ foram escorregamentos ou início de escorregamento. A terminologia "início de escorregamento" foi retirada do cadastro do trabalho de Bonuccelli (1999). A figura 2 mostra a distribuição das ocorrências de escorregamentos na cidade por ano.

Paralelamente à organização do cadastro, foram realizadas visitas de campo, para reconhecimento das áreas dos acidentes e plotagem das ocorrências em um mapa viário do município, gentilmente cedido pela Prefeitura Municipal, complementando o mapa de cadastro de movimentos de massa de Bonuccelli (1999).
Através do mapa final dos registros, foi possível visualizar os principais pontos da cidade onde ocorrem os maiores problemas relacionados aos acidentes de movimentos de massa e delimitar as áreas de maior incidência dos mesmos.

DEFINIÇÃO DAS ÁREAS CRÍTICAS Para a elaboração da Carta Cadastral de Escorregamentos (escala 1:10.000), foi necessária a criação de uma base cartográfica digital da área urbana de Ouro Preto, além de um sistema de informações geográficas, utilizando recursos de geoprocessamento (software Arc Map, versão 9.0). Este processo de georreferenciamento dos registros do cadastro foi elaborado por Gomes (2005). A base cartográfica da área urbana de Ouro Preto foi obtida a partir do mapa viário da área urbana da cidade (Prefeitura de Ouro Preto 2004, na escala 1:2.000), complementada com a topografia na escala de 1:5.000 da Planag (1974). Posteriormente foi realizada a locação das ocorrências dos movimentos de massa cadastrados a partir de mapa anterior (Bonuccelli 1999), complementado com as ocorrências posteriores.

Com a elaboração deste mapa cadastral dos escorregamentos, foi possível destacar os locais mais afetados em cada ano, os bairros mais críticos e analisar a evolução dos movimentos de massa ao longo de todos os anos da pesquisa. 


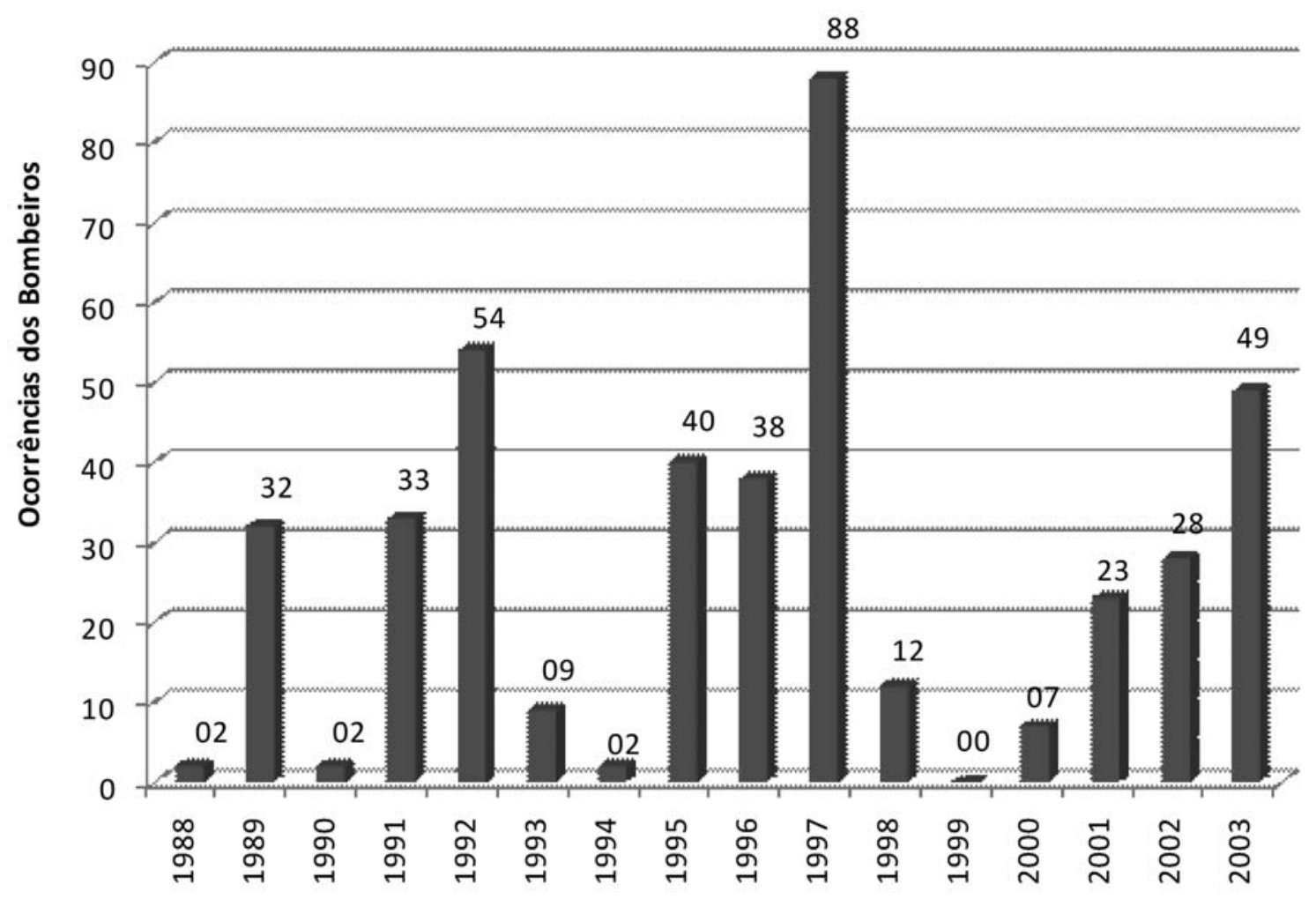

Figura 2 - Distribuição das ocorrências de escorregamentos na cidade por ano.

No mapa com a série completa dos registros de movimentos de massa foi realizado o zoneamento de risco. Os critérios utilizados para a classificação foram a concentração de movimentos na região, a extensão da área atingida, sendo também avaliada em campo a vulnerabilidade de cada zona delimitada (condições construtivas e densidade de ocupação). Assim, as zonas de risco foram divididas em três níveis: Risco Baixo (pequena concentração em pequenas áreas), Risco Médio (pequenas concentrações em grandes áreas) e Risco Alto (grandes concentrações em grandes áreas).

A tabela 1 mostra os critérios da classificação das áreas e na figura 3 está representado o zoneamento das áreas críticas de Ouro Preto em relação a escorregamentos.

\section{CORRELAÇÃO PLUVIOSIDADE E ESCORRE-} GAMENTOS Para Tatizana et al. (1987), a distribuição de chuva é uma importante variável no ciclo hidrológico, com influências na taxa de saturação do solo e no desenvolvimento de fenômenos instantâneos, como desenvolvimento de linhas de fluxo, subpressão e erosão. Delmonaco et al (1995) afirmam que, de forma geral, os movimentos de massa profundos estão relacionados a chuvas antecedentes acumuladas de vários dias, enquanto que movimentos de massa superficiais são mais dependentes da intensidade e duração da chuva em períodos mais curtos. Desta forma, geralmente os estudos de correlação de chuvas e movimentos de massa consideram tanto a precipitação no momento do evento, como o acumulado em período anterior.

Foram desenvolvidos diversos trabalhos relacionando a pluviosidade com movimentos de massa, no Brasil e no mundo. Os principais foram o de Lumb (1975) e de Kay \& Chen (1995), ambos em Hong Kong. No Brasil, o trabalho de maior contribuição foi realizado por Tatizana et al. (1987) para a Serra do Mar, entre Santos e São Paulo, no qual se estabeleceu o número de dias de chuva acumulada que influencia na deflagração dos movimentos e uma curva denominada envoltória de escorregamento, que correlaciona a chuva acumulada em quatro dias com a chuva horária do momento do escorregamento. Além de Tatizana,

Tabela 1 - Classificação das áreas críticas de Ouro Preto.

\begin{tabular}{cccc}
\hline Nível & Risco & Concentração & Área \\
\hline 0 & Mínimo & Esparsos & Espalhados \\
\hline 1 & Baixo & Pequena & Pequenas \\
\hline 2 & Médio & Pequena & Grandes \\
\hline 3 & Alto & Grande & Grandes \\
\hline
\end{tabular}




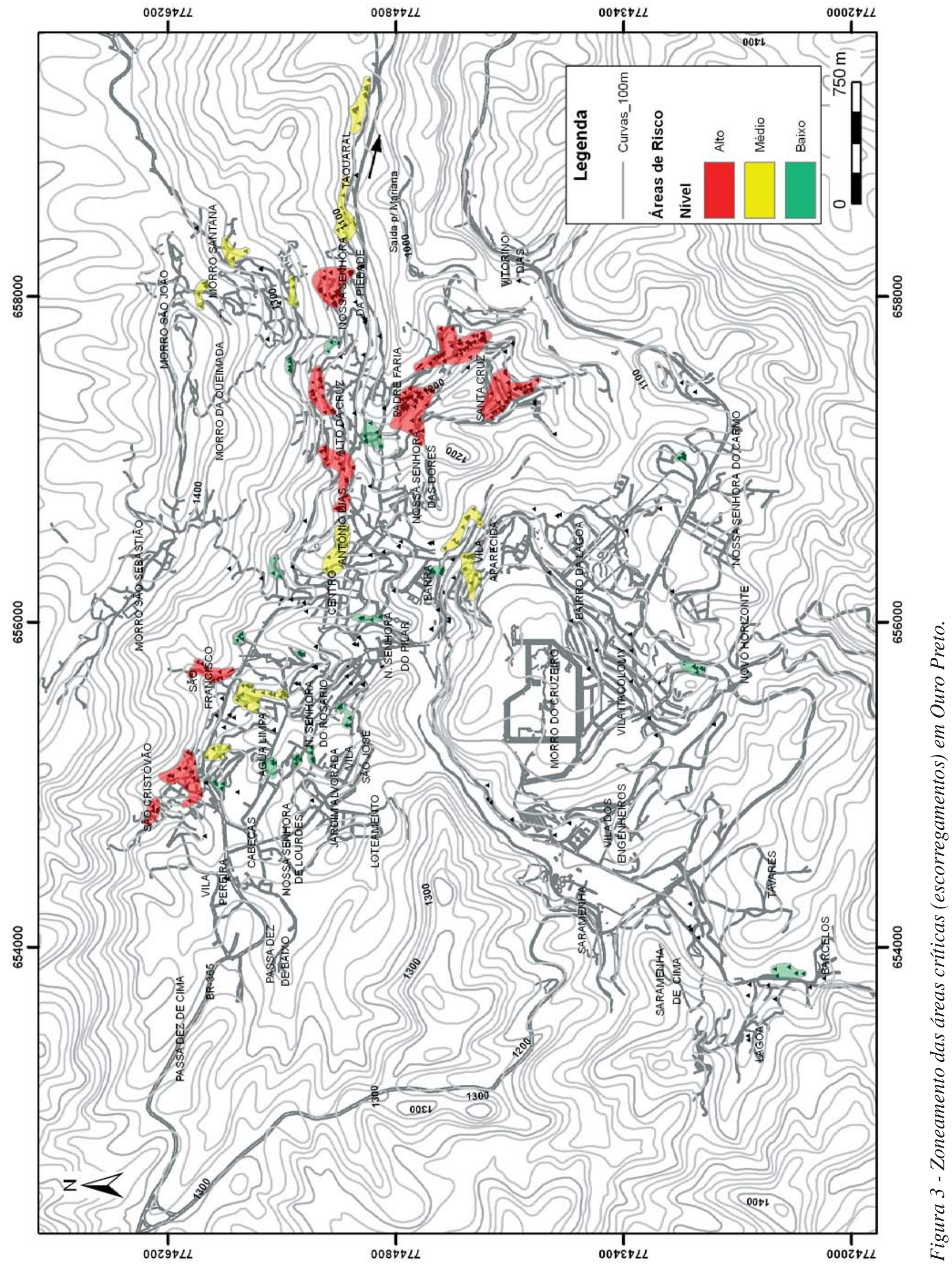


foram elaborados trabalhos de correlação por Elbachá et al. (1992) em Salvador/BA, Xavier (1996) para Belo Horizonte/MG, Salaroli (2003) em Vitória/ES e Ide (2005) para Campinas/SP.

A metodologia do trabalho de Tatizana et al. (1987) consiste na comparação dos valores das chuvas acumuladas que causaram ou não ocorrências de escorregamentos, através da construção de diagramas de dispersão. Posteriormente, foi proposta a construção de uma envoltória de escorregamento, que fornece uma relação entre a precipitação acumulada e a precipitação na hora da ocorrência. Foi encontrada para a Serra do Mar a seguinte equação de correlação entre pluviosidade e escorregamentos: I = $2603 \times \mathrm{AC}^{-0,933}$, sendo I a intensidade horária $(\mathrm{mm} / \mathrm{h})$ e AC a acumulada de chuvas em 4 dias anteriores (mm).

Este trabalho seguiu a metodologia proposta por Tatizana et al. (1987), no entanto, foi utilizada a chuva diária nas correlações e não a chuva horária conforme a metodologia desenvolvida. Isto ocorre pela falta de dados pluviográficos na região.

Para correlacionar a pluviosidade e os movimentos de massa, para Ouro Preto, foi necessário realizar uma triagem nos dados cadastrados limitando-os pela tipologia, sendo analisados apenas os casos de escorregamentos. Essa escolha deve-se a maior influência da precipitação na sua deflagração, a maior quantidade de dados e aos melhores resultados obtidos. Por questões práticas foram selecionados os períodos que registraram um maior número de ocorrências (1989, 1991, 1992, 1995, 1996/1997, 2001/2002 e 2002/2003).

A correlação tem por objetivo estabelecer uma relação numérica entre os níveis pluviométricos e a possibilidade de deflagração de escorregamentos que possa ser utilizada para a previsão dos acidentes e tendo aplicação direta nos planos de defesa civil dos municípios.

Inicialmente foram verificados os dias de chuva antecedentes que influenciam na deflagração dos escorregamentos, através de análises de gráficos comparativos entre os registros pluviométricos que provocaram escorregamentos e aqueles que não provocaram. O valor que apresentou o melhor resultado foi de cinco dias de chuvas antecedentes (acumuladas).

Posteriormente, buscou-se uma relação matemática entre a precipitação diária e acumulada em cinco dias anteriores ao acidente. Para tal, foram lançados os pontos com e sem escorregamentos em gráfico da chuva diária pela chuva acumulada. A equação foi obtida através da adição de uma linha de tendência aos pontos que definem uma separação dos pontos com e sem escorregamentos.

Para uma melhor definição foram excluídos 42 dados de escorregamentos isolados, ou seja, registros em que só houve uma ocorrência por dia. Isto foi necessário por estas ocorrências se caracterizarem como tendo nitidamente uma influência antrópica (cortes ousados, disposição de resíduos etc.). Esta análise possibilitou uma melhor visualização dos registros mais severos, que podem causar maiores prejuízos para a cidade.

O gráfico encontrado (Fig. 4) mostra a separação dos pontos com e sem escorregamentos, definida pela curva apresentada e pela equação seguinte: $\mathrm{PD}=$ 6386,6 $\times \mathrm{PA}^{-1,3847}$, sendo PD a precipitação diária no dia da ocorrência e PA a precipitação acumulada em cinco dias, excluindo a precipitação do dia do escorregamento. O valor do coeficiente de determinação da curva $\left(\mathrm{R}^{2}\right)$ foi satisfatório, atingindo o valor de 0,9819 , significando boa concordância dos pontos com a linha de tendência adicionada.

\section{PLANOS PREVENTIVOS DE DEFESA CIVIL} (PPDC) Os planos preventivos de defesa civil (PPDC) e os sistemas de alerta são instrumentos de prevenção de acidentes naturais e/ou tecnológicos induzidos ou não pela ação antrópica. Sua concepção prevê o planejamento de ações que deverão ser tomadas antes, durante e depois de situações de risco, a fim de que se possam reduzir os prejuízos socioeconômicos e o número de vítimas fatais nessas ocasiões. Estes planos podem e devem ser elaborados a partir do risco eminente de cada cidade.

As medidas a serem tomadas se baseiam na previsão das condições favoráveis à ocorrência das situações de risco. No caso de escorregamentos, os parâmetros que deverão ser acompanhados são os índices pluviométricos do local, as previsões meteorológicas e observações feitas regularmente a partir de vistorias de campo.

No Brasil são mais comuns os planos para a prevenção contra escorregamentos, enchentes e inundações. Dentre estes, os mais conhecidos são: o Plano Preventivo de Defesa Civil do Estado de São Paulo, descrito por Macedo (2003) e o Sistema Alerta Rio (RJ), gerenciado pela GEORIO, descrito por d'Orsi et al. (1997) e d'Orsi et al. (2004).

Ouro Preto, apesar de possuir diversas áreas vulneráveis a movimentos de massa, ainda não possui um órgão de defesa civil instituído. A implantação já está em andamento, com a votação do projeto de Lei que cria a Coordenadoria Municipal de Defesa Civil (COMDEC). Enquanto aguarda a legitimação da sua criação, a COMDEC atua apenas com vistorias nas residências que solicitam o atendimento. Com a criação da COMDEC, um plano preventivo deverá ser elaborado, pois como visto nos tópicos anteriores, muitos itens que são necessários para a elaboração de um plano preventivo de defesa civil já existem para Ouro Preto.

Na tabela 2 está proposta uma relação dos níveis de PPDC aplicado a Ouro Preto, baseado nos resultados encontrados no trabalho de Castro (2006). Junto 


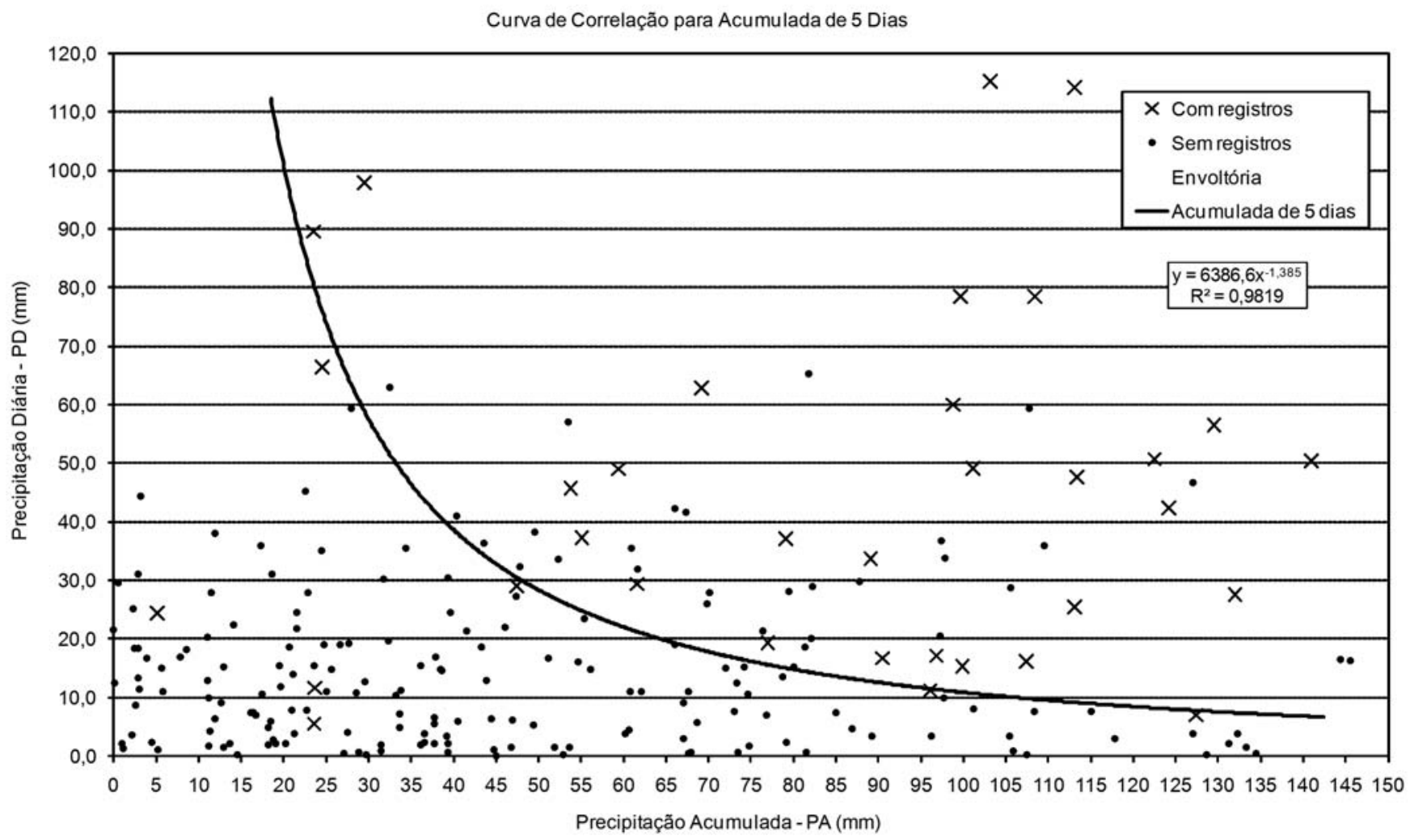

Figura 4 - Curva de correlação entre precipitação diária e acumulada para cinco dias para escorregamentos generalizados.

Tabela 2 - Níveis do PPDC proposto para Ouro Preto (Castro 2006).

\begin{tabular}{cccc}
\hline Nível & Índice Pluviométrico & Critério de Entrada & Ações específicas \\
\hline Observação & 0,0 a $22,0 \mathrm{~mm} / 5$ dias & Início do PPDC & $\begin{array}{c}\text { Acompanhamento dos índices pluviométricos } \\
\text { e da meteorologia }\end{array}$ \\
\hline Atenção & 22,0 a $128,0 \mathrm{~mm} / 5$ dias & $\begin{array}{c}\text { Início das chuvas prolongadas e pre- } \\
\text { visões meteorológicas }\end{array}$ & $\begin{array}{c}\text { Vistorias de campo nas áreas de risco e acom- } \\
\text { panhamento dos índices pluviométricos }\end{array}$ \\
\hline Alerta & Acima de $128,0 \mathrm{~mm} / 5$ dias & $\begin{array}{c}\text { Aspectos de instabilidade nas áreas } \\
\text { de riscos ou em proximidades; pre- } \\
\text { visão da continuidade das chuvas. }\end{array}$ & $\begin{array}{c}\text { Vistorias de campo nas áreas de risco, re- } \\
\text { moção da população. }\end{array}$ \\
\hline
\end{tabular}

à proposição dos níveis estão expostos os critérios de entrada com os valores de chuva acumulada em cinco dias e as ações específicas relacionadas a cada nível, baseadas nos PPDC existentes na literatura.

Para a operação do PPDC em Ouro Preto, seria necessário o monitoramento das chuvas, instalando uma rede de pluviômetros, capaz de medir a precipitação ocorrida em pontos estratégicos nas áreas mais afetadas pelos movimentos de massa. Para a capacitação do Corpo de Bombeiros ou equipe designada pela prefeitura, para a identificação dos tipos de movimentos e realização do monitoramento das feições de instabilidades, poderiam ser realizados treinamentos com cursos e palestras, além do envolvimento da população para atuar como voluntária para a defesa civil.

CONSIDERAÇÕES FINAIS Neste trabalho foram apresentadas as áreas onde ocorre a maior concentração de acidentes relacionados a movimentos de massa em Ouro Preto, demonstrando os lugares que necessitam de intervenções para a prevenção dos escorregamentos. Foi realizado um zoneamento das áreas de risco, classificando-as em alto, médio e baixo risco, de acordo com a quantidade de registros de 
ocorrências, tamanho da área afetada e as condições locais verificadas em trabalhos de campo.

A correlação da precipitação com escorregamentos mostrou que a quantidade de chuva acumulada em cinco dias influencia a deflagração dos mesmos, provocando a saturação do solo, favorecendo a ruptura. Baseado nesta correlação foi estimado o valor de 22,0 mm de chuva acumulada em cinco dias para o início dos escorregamentos. Para valores acima de 128,0 mm/5 dias a probabilidade de eventos mais severos aumenta. Esses valores poderão ser utilizados no monitoramento das chuvas diárias para servir de base para intervenções e mudanças de níveis de um PPDC.

A equação que correlaciona a chuva diária com a chuva acumulada foi uma equação do tipo potência, que melhor se ajustou à curva. A equação encontrada foi: $\mathrm{PD}=6386,6 \times \mathrm{PA}^{-1,3847}$, sendo PD a precipitação diária do dia do escorregamento e PA a precipitação acumulada, excluindo a precipitação do dia do acidente. Essa equação pode ser utilizada no monitoramento das chuvas acumuladas para a prevenção aos escorregamentos.

As causas da ocorrência de escorregamentos vão além da quantidade de chuva ocorrida no dia e nos dias anteriores. Outros fatores são importantes para seu desencadeamento, tais como as propriedades geológicas e geomorfológicas do local e o processo de ocupação. Esses fatores não foram escopos deste trabalho, mas são dados importantes a serem pesquisados em estudos futuros.

Agradecimentos Os autores agradecem à Prefeitura de Ouro Preto pela cessão das bases cartográficas, ao Corpo de Bombeiros de Ouro Preto, pela disponibilização do cadastro de ocorrência, à Novelis pelo fornecimento dos dados pluviométricos e à FAPEMIG, pelo suporte financeiro.

\section{Referências}

Bonuccelli T. \& Zuquette L.V. 1999. Movimentos gravitacionais de massa e erosões na cidade histórica de Ouro Preto, Brasil. Revista Portuguesa de Geotecnia, 85:59-80.

Bonuccelli T. 1999. Estudos dos movimentos gravitacionais de massa e processos erosivos com aplicação na área urbana de Ouro Preto (MG), na escala 1:10.000. Tese de Doutorado, Escola de Engenharia de São Carlos, USP, São Carlos, 191 p.

Carvalho E.T. 1982. Carta Geotécnica de Ouro Preto. Dissertação de Mestrado, Universidade Nova Lisboa, Lisboa, 92 p.

Castro J.M.G. 2006. Pluviosidade e Movimentos de Massa em encostas de Ouro Preto. Dissertação de Mestrado, Universidade Federal de Ouro Preto, Ouro Preto, 110 p.

Delmonaco G., Ippolito F., Margottini C. 1995. The CEC Project. Meteorological Factors influencing slope stability and slope movement type: evaluation of hazard prone areas. In: Hydrological and Hydrogeological Risks: Proceedings of the First Review Meeting, 1, Anais, p. 259-283.

d’Orsi R.N., D’Avila C., Ortigao J.A.R., Dias A., Moraes L., Santos M.D. 1997. Rio-Watch: The Rio de Janeiro landslide watch system. In: ABGE, Conferência Brasileira sobre Estabilidade de Encostas, 2, Anais, p. 21-30.

d’Orsi R.N., Feijó R.L., Paes N.M. 2004. 2.500 Operational days of Alerta Rio System: History and Technical Improvements of Rio de Janeiro Warning System for Severe Weather. In: International Symposium on Landslides, 9, Anais, p. 831-836.

Elbachá A.T., Campos L.E.P., Bahia R.F.C. 1992. Tentativa de correlação entre precipitação e deslizamentos na cidade de Salvador. In: ABMS, Conferência Brasileira sobre estabilidade de Encostas, 1, Anais, p. 647-656.

Gomes G.J.C. 2005. Análise temporal e espacial do risco de escorregamento em Ouro Preto - MG utilizando um Sistema de Informação Geográfica. Trabalho de Graduação, Engenharia Ambiental, Universidade Federal de Ouro Preto, Ouro Preto, 45 p.

Gomes R.C., Araújo L.G., Bonuccelli T., Sobreira F.G. 1998. Condicionantes Geotécnicos do Espaço Urbano de Ouro Preto/MG. In: ABMS, Congresso Brasileiro de Mecânica dos Solos e Engenharia Geotécnica, 11, Anais, p. 363-370.

Ide F.S. 2005. Escorregamento, meteorologia e precipitação: uma proposta de método de investigação para a prevenção e monitoramento de riscos, aplicado em Campinas/SP. Dissertação de Mestrado, Instituto de Pesquisas Tecnológicas do Estado de São Paulo, São Paulo, 153 p.

Kay J.N. \& Chen T. 1995. Rainfall-landslide relationship for Hong Kong. Proceedings of the ICE - Geotechnical Engineering, 113:117-118.

Lumb P. 1975. Slope failures in Hong Kong. Quarterly Journal of Engineering Geology and Hydrogeology, 8:31-35.

Macedo E.S. 2003. Plan Preventivo de Defensa Civil (PPDC). In: Ferrero A. (ed.) Hábitat en Riesgo, Experiencias Latinoamericanas. Cordoba, Ed. CYTED, p. 89-95.

PLANAG. 1974. Levantamento aerofotogramétrico e restituição da cidade de Ouro Preto. Foto aérea, Ouro Preto, escala 1:2.000.

Prefeitura Municipal de Ouro Preto. 2004. Mapa viário da área urbana da cidade de Ouro Preto. Ouro Preto, mapa viário, escala 1:2.000.

Salaroli I.S. 2003. Movimentos de Massa no Município de Vitória - ES: inventário, caracterização e indicativos de um modelo comportamental. Dissertação de Mestrado, Universidade Federal do Espírito Santo, Vitória, 143 p.

Sobreira F.G. 1989. A ocupação desordenada de encostas 
Proposição de procedimento preventivo de riscos geológicos em Ouro Preto - BR com base em histórico de ocorrências e sua correlação com a pluviosidade

na cidade de Ouro Preto. Revista da Escola de Minas, 42(4):12-16.

Sobreira F.G. 1990. Levantamento de áreas de riscos no espaço urbano de Ouro Preto - MG. Ouro Preto, IPHAN/ UFOP/MinC, Relatório Técnico, 87 p.

Sobreira F.G., Araújo L.G., Bonuccelli T. 1990. Levantamento de soluções estruturais para a contenção de encosta em Ouro Preto. Ouro Preto, IPHAN/UFOP/MinC, Relatório Técnico, $91 \mathrm{p}$.

Souza M.L. 1996. Mapeamento geotécnico da cidade de Ouro Preto / MG (escala 1:10.000) - Susceptibilidade aos movimentos de massa e processos correlatos. Dissertação de Mestrado, Escola de Engenharia de São Carlos, USP, São Carlos, 2 v.
Tatizana C., Ogura A.T., Cerri L.E.S., Rocha M.C.M. 1987. Análise de Correlação entre Chuvas e Escorregamentos - Serra do Mar, Município de Cubatão. In: ABGE, Congresso Brasileiro de Geologia de Engenharia, 5, Anais, p. 225-236.

Xavier H. 1996. Percepção geográfica dos deslizamentos de encostas em áreas de risco no município de Belo Horizonte, MG. Tese de Doutorado, Instituto de Geociências e Ciências Exatas, Universidade Estadual Paulista, Rio Claro, 222 p.

Manuscrito ID 17284

Submetido em 12 de abril de 2010 Aceito em 07 de fevereiro de 2012 